\title{
Building Tensegrity Structures to Explore Interactions Between Tension and Compression (P12 Resource Exchange)
}

\section{Prof. Vicki V. May, Dartmouth College}

Vicki V. May, Ph.D., P.E. is an Associate Professor of Engineering at Dartmouth College. Her research focuses on engineering education and K-12 outreach. She teaches courses in solid mechanics, structural analysis, and integrated design at Dartmouth. Prior to relocating to the east coast, Professor May was an Associate Professor of Architectural Engineering at the California Polytechnic State University in San Luis Obispo. 


\section{Building Tensegrity Structures to Explore Interactions between Tension and Compression}

(P12 Resource Exchange)

Contact Information: Vicki V. May, PhD, PE, Instructional Associate Professor, Thayer School of Engineering, Dartmouth College, 14 Engineering Drive, Hanover, NH 03755. vicki.v.may@dartmouth.edu.

Background/Description: Tension and compression, or pushing and pulling, are important concepts in the engineering of solid systems from structures to mechanical devices to biological systems and more. Tension and compression rarely act in isolation. By building tensegrity structures students are able to feel how tension and compression work together to stabilize a structure. Basic tensegrity structures are fairly easy to build using rubber bands and wooden dowels. During this session, participants will be introduced to tensegrity and will build basic tensegrity structures that they may keep.

This activity is one of several activities that were developed as part of a massive open online course entitled The Engineering of Structures Around Us: https://www.edx.org/course/engineering-structures-around-us-dartmouthx-dart-engs-01-x.

Grade Levels: The targeted grade levels for this activity are $5^{\text {th }}$ through $8^{\text {th }}$ grades but it has been used with both younger and older students (including college students).

Learning Objectives: Through this activity students will build basic 3-dowel and 6-dowel tensegrity structures as well as begin to design structures of their own; identify tension and compression in the structures; and begin to feel how tension and compression work together to stabilize structures.

Materials: In order to build a 3-dowel and 6-dowel tensegrity structure each student will need 9 wooden dowels ( 1/8" in diameter and 4-6" in length) and $9+$ rubber bands (size \#32 bands work well). These materials will be provided to workshop participants.

Procedure: Step by step instructions for creating 3-dowel and 6-dowel tensegrity structures are provided on the following pages. Videos discussing tensegrity in general and how to build basic tensegrity structures are available here: https://www.youtube.com/watch?v=SP3JSw3TPrM and https://www.youtube.com/watch?v=xdoJEyDhnyQ.

\section{$\underline{\text { 3-dowel Tensegrity Structure }}$}

Step 1: Place two dowels in a crossed shape (X-shape) and add one elastic band that goes around all four ends.

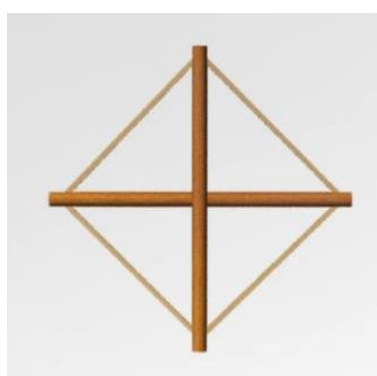


Step 2: Place the third dowel perpendicular to the other two dowels and add an elastic band around the two ends of the new dowel and both ends of one of the original dowels. Feel how the structure moves as you displace it.

Step 3: Add a third dowel perpendicular to the other two and add the final elastic band around the ends of this third dowel that you added and one of the other dowels such that each dowel has two bands connected at each end. How does it feel now when you try to displace the structure? It should feel more stable.

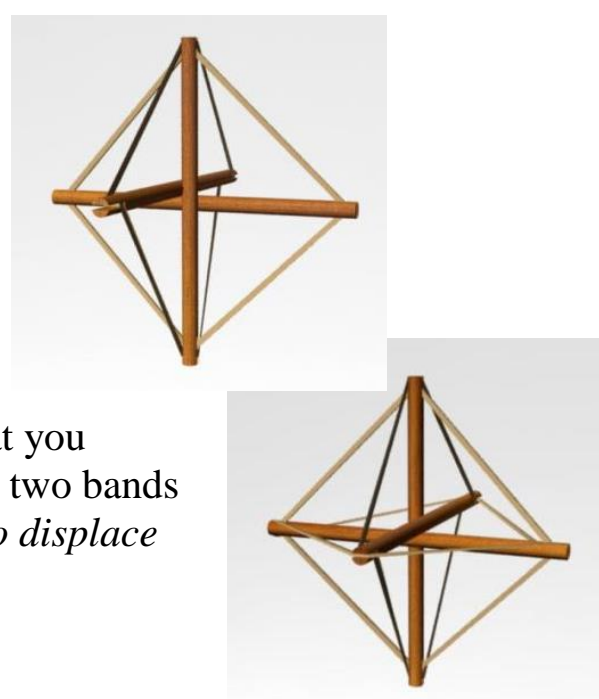

\section{6-dowel Tensegrity Structure}

Step 1: Put an elastic band around each of 6 dowels. This will make the upcoming processes a little easier. Group the dowels into three groups, with two dowels in each group.

Step 2: Place two dowels from the same group parallel to

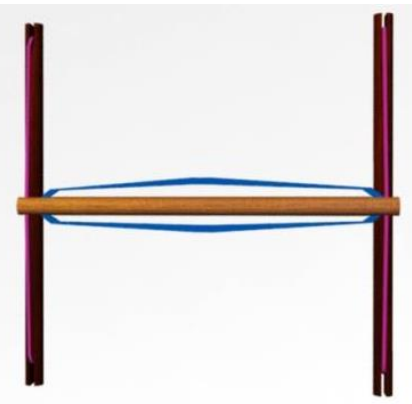
each other. Add one dowel from a different group perpendicular to and in the middle of the

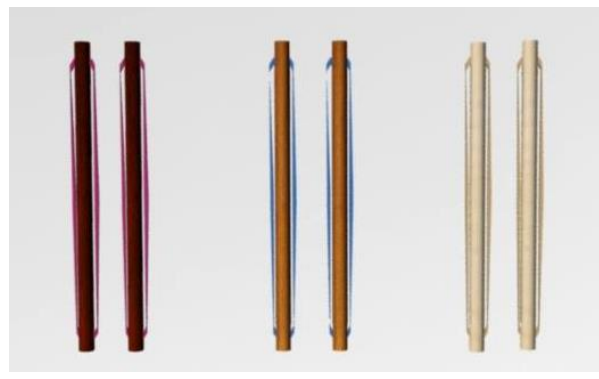
original two dowels, so that it looks like an $\mathrm{H}$.

Step 3: Flip over and repeat with the other dowel from the same group so that there is one perpendicular dowel on either side of the original pair.

Step 4: Add the last pair of dowels so that they are perpendicular to both sets dowels that have already been put together, connecting the ends to the loose elastic bands (shown in blue in these images).

Step 5: Add the last elastic band such that each dowel has two bands connected at each end and adjust the lengths in between to balance out the tension. This last step can be a little hard as there is a lot of tension and compression built up, so be careful!

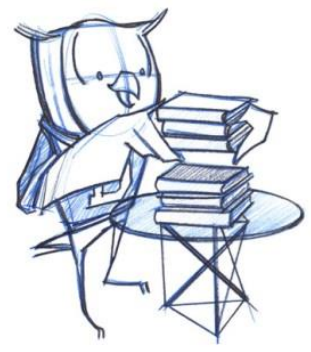

\section{Moving on!}

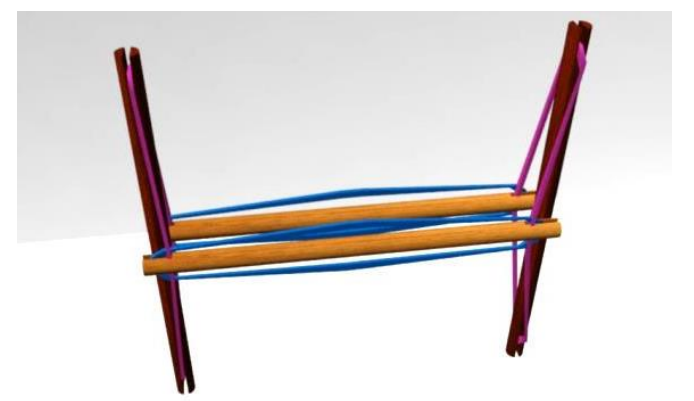

Once you've built a couple of basic tensegrity structures go ahead and build a tensegrity structure of your own design. How do the different components act in a tensegrity structure? Can your tensegrity structure support a load? What happens if you remove an elastic band from one end of a dowel? 